Brit. Heart f., 1968, 30, 546.

\title{
New Concepts of Intramural Myocardial Conduction in Hypertrophic Obstructive Cardiomyopathy
}

\author{
JAMES J. COYNE* \\ From the Department of Medicine (Clinical Cardiology), Royal Postgraduate Medical School and Hammersmith \\ Hospital, London
}

The electrocardiographic findings in hypertrophic obstructive cardiomyopathy are often similar to myocardial infarction, occasionally resemble anomalous atrioventricular excitation, seem to mimic right ventricular hypertrophy, and usually indicate left ventricular hypertrophy (Goodwin et al., 1960; Braunwald et al., 1960; Hollister and Goodwin, 1963; Prescott, Quinn, and Littmann, 1963; Braudo, Wigle, and Keith, 1964; Marriott, 1964). Vectorcardiographic reports of small series, on the other hand (Wood et al., 1962; Estes et al., 1963), have been inconclusive except for the findings of Oberwittler et al. (1965) of peripheral loop deformities. Septal hypertrophy, the generally accepted crux of this disease, is also thought to be the origin of the pathological $\mathrm{q}$ waves which mimic myocardial infarction. Interestingly, septal hypertrophy is found in every instance of hypertrophic obstructive cardiomyopathy, whereas pathological q waves are probably observed in only 10 per cent of cases (Braudo et al., 1964). It seems that a more precise understanding of the transseptal activation process is required to explain this disparity.

Activation of the interventricular septum has been documented electrophysiologically (Scher and Young, 1957; Amer et al., 1960), and Sodi Pallares et al. (1957) state that septal vectors can be recognized in the sequence of ventricular activation by vectorcardiographic recordings.

With the knowledge that the interventricular septum is usually massive in hypertrophic obstructive cardiomyopathy, a vectorcardiographic analysis was undertaken to study septal excitation within the

\footnotetext{
Received November 22, 1967.

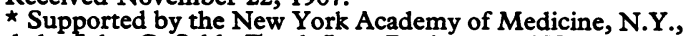
and the John C. Sable Fund, Inc., Rochester, N.Y.

Present address: 807, Medical Group, March, A.F.B., Riverside, California, U.S.A.
}

sequence of ventricular activation. From this study attempts are made to classify and explain the vectorcardiographic findings on the basis of altered intramural activation processes from muscle conduction disturbances.

\section{SUBJECTS AND METHODS}

Thirty-three patients, 18 male and 15 female, ranging in age from 4-59 years, were available for vectorcardiography. All patients were clinically evaluated at Hammersmith Hospital and the Royal Postgraduate Medical School, and except for Case 33 (see Table III) were diagnosed as having hypertrophic obstructive cardiomyopathy on clinical and either left ventricular haemodynamic or angiocardiographic criteria (Cohen et al., 1964). None had been operated upon, though many were taking propranolol. The Grishman cube system of electrode placement was used as the vectorcardiographic system. Vectorcardiograms were recorded on photographic paper by an Electronics for Medicine Model DR8. The electron beam was interrupted every $4 \mathrm{msec}$. Three or more vectorcardiograms were recorded of each plane, for detailed clarity of initial vectors. Septal activation was thought to be nearly complete at $24 \mathrm{msec} . \pm 4 \mathrm{msec}$. (Scher and Young, 1957). The main septal vector when present and the $R$ vector were analysed by the method of Estes et al. (1963). The vector angles were measured from a conventional $360^{\circ}$ reference system, as was the QRS-T angle. Duration of inscription was measured by counting the blips, and the speed of inscription was determined by analysis of the blips in relation to the whole loop. Slow inscription was indicated when at least 5 blips were small and close together, as recorded in at least 2 planes. The $T$ wave was thought to be discordant when the main QRS to main $\mathrm{T}$ vector angle exceeded $90^{\circ}$.

Standard 12-lead electrocardiograms $(1.0 \mathrm{mV}=1 \mathrm{C}$ $\mathrm{mm}$.) were recorded by an Elema-Schonander Mingograph, Model 42B. The criteria of Sokolow and Lyon (1949) for left ventricular hypertrophy were included in analysing the electrocardiogram. 


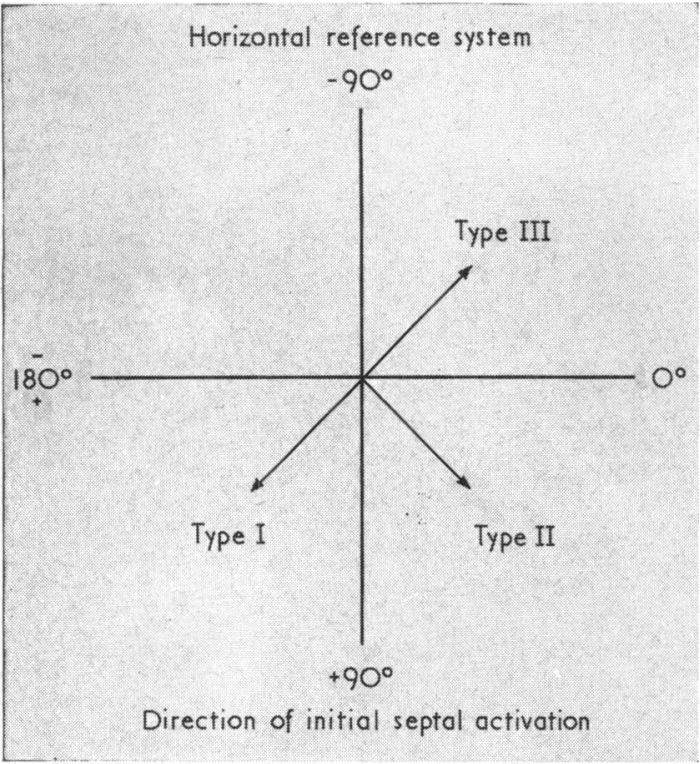

Fig. 1.-Types of vectorcardiograms seen in hypertrophic obstructive cardiomyopathy based on the direction of the initial septal activation process in the horizontal plane.

\section{RESULTS}

Analysis of the vectorcardiograms showed three types of loops which were distinguished by the direction of the initial septal activation in the horizontal plane (Fig. 1). The types are: Type I.
Initial septal vectors anteriorly and to the right $\left(+90^{\circ}+180^{\circ}\right)$. Type II. Initial septal vectors anteriorly and to the left $\left(0^{\circ}+90^{\circ}\right)$. Type III. Initial septal vectors posteriorly and to the left $\left(0^{\circ}-90^{\circ}\right)$.

Type I vectorcardiograms, revealing the normal direction of septal activation, were seen in 19 (13 male and 6 female) out of 33 patients, whose ages ranged from 4-59 years (Table I). Six patients with Type I had $\mathrm{QRS}_{\mathrm{H}}$ loops of a figure-of-eight pattern, with the distal loop inscribed in a clockwise fashion. In 2 of the latter types (Cases 1 and 12) the distal segment of the figure-of-eight loop was greater than $1 \mathrm{mV}$ in width (Fig. 2 and 3A). Two (Cases 1 and 11) had a "pigtail curl" on either the efferent or afferent limb of the $\mathrm{QRS}_{\mathrm{H}}$ loop (Fig. 3).

Slow inscription of the septal vectors (Fig. 2) was observed in 13 of 19 cases and the scalar electrocardiogram of one of these (Case 15, Fig. 4) is suggestive of anomalous atrioventricular excitation. The vectorcardiogram of the latter revealed slow septal inscription in the $Q R S_{H}$ and the $Q R S_{R . S a g}$ loops. Two cases (8 and 6) had a large main septal vector, anteriorly and to the right, measuring 1.0 $\mathrm{mV}$ and $1.5 \mathrm{mV}$, respectively (Fig. 5). The main septal vector was also superior in these youths. The scalar electrocardiograms in both cases were strongly suggestive of right ventricular hypertrophy and inferior and lateral wall infarction.

There were two examples of right bundle-branch block in Type I. The main $P$ wave vector was greater than $0.25 \mathrm{mV}$ in only 4 of the 19 cases. The

TABLE I

COMPARISON OF CLINICAL, HAEMODYNAMIC, AND ELECTROCARDIOGRAPHIC FINDINGS IN TYPE I HYPERTROPHIC OBSTRUCTIVE CARDIOMYOPATHY

\begin{tabular}{|c|c|c|c|c|c|c|c|c|}
\hline \multicolumn{3}{|c|}{$\begin{array}{l}\text { Case No., } \\
\text { age (yr.), } \\
\text { and sex }\end{array}$} & \multirow{2}{*}{ Syncope } & \multirow{2}{*}{$\frac{\text { Angina }}{0}$} & \multirow{2}{*}{$\begin{array}{c}\begin{array}{c}\text { Left ventricular end- } \\
\text { diastolic pressure } \\
\text { (mm. Hg) }\end{array} \\
3\end{array}$} & \multicolumn{2}{|c|}{$\begin{array}{l}\text { Resting } \\
\text { LV-AO } \\
\text { gradient }\end{array}$} & \multirow{3}{*}{$\begin{array}{l}\text { Electrocardiographic similarities } \\
\text { Lt. bundle-branch block with } \\
\text { complexes } \\
\text { Lt. axis deviation }\end{array}$} \\
\hline & & $\mathbf{M}$ & & & & & $65 \ddagger$ & \\
\hline $\begin{array}{l}2 \\
3 \\
4 \\
5 \\
6\end{array}$ & $\begin{array}{l}2 \\
51 \\
16 \\
17 \\
11\end{array}$ & $\begin{array}{l}\mathbf{F} \\
\mathbf{F} \\
\mathbf{M} \\
\mathbf{M} \\
\mathbf{M}\end{array}$ & $\begin{array}{l}\mathbf{0} \\
\mathbf{0} \\
\mathbf{0} \\
\mathbf{0} \\
\mathbf{0}\end{array}$ & $\begin{array}{l}0 \\
+ \\
0 \\
0 \\
0\end{array}$ & $\frac{20}{20}$ & $\begin{array}{r}0 \\
40 \\
0 \\
25\end{array}$ & & \\
\hline $\begin{array}{l}7 \\
8\end{array}$ & $\begin{array}{r}43 \\
4\end{array}$ & $\begin{array}{l}\mathbf{M} \\
\mathbf{M}\end{array}$ & $\begin{array}{l}\mathbf{0} \\
\mathbf{0}\end{array}$ & $\stackrel{+}{0}$ & $\begin{array}{l}20 \\
10\end{array}$ & $\begin{array}{l}90 \\
60\end{array}$ & & $\begin{array}{l}\text { Anterior lateral infarction } \\
\text { Rt. ventric. hypertrophy, anterior }\end{array}$ \\
\hline $\begin{array}{r}9 \\
10\end{array}$ & $\begin{array}{l}27 \\
31\end{array}$ & $\begin{array}{l}\mathbf{M} \\
\mathbf{M}\end{array}$ & $\begin{array}{l}\mathbf{0} \\
\mathbf{0}\end{array}$ & $\begin{array}{l}0 \\
+\end{array}$ & $\begin{array}{r}7 \\
10\end{array}$ & $\begin{array}{r}0 \\
70\end{array}$ & & Rt. bundle-branch block, lt. axis \\
\hline $\begin{array}{l}11 \\
12 \\
13 \\
14 \\
15 \\
16 \\
17 \\
18 \\
19\end{array}$ & $\begin{array}{l}53 \\
16 \\
36 \\
46 \\
47 \\
28 \\
52 \\
59 \\
19\end{array}$ & $\begin{array}{l}\mathbf{M} \\
\mathbf{M} \\
\mathbf{M} \\
\mathbf{F} \\
\mathbf{F} \\
\mathbf{M} \\
\mathbf{M} \\
\mathbf{F} \\
\mathbf{F}\end{array}$ & $\begin{array}{l}0 \\
0 \\
0 \\
+ \\
+ \\
0 \\
0 \\
0 \\
0\end{array}$ & $\begin{array}{l}0 \\
0 \\
0 \\
+ \\
0 \\
0 \\
0 \\
+ \\
0\end{array}$ & $\begin{array}{r}10 \\
5 \\
8 \\
10 \\
18 \\
15 \\
17 \\
20 \\
32\end{array}$ & $\begin{array}{r}10 \\
90 \\
0 \\
0 \\
45 \\
120 \\
75 \\
0 \\
15\end{array}$ & $\begin{array}{l}40 \ddagger \\
50 \ddagger\end{array}$ & $\begin{array}{l}\text { Anomalous AV excitation } \\
\text { Anomalous AV excitation } \\
\text { Rt. bundle-branch block } \\
\end{array}$ \\
\hline
\end{tabular}

* QRS findings other than left ventricular hypertrophy.

+ , present; 0 , absent; -, not measured; $¥$ induced gradient. 


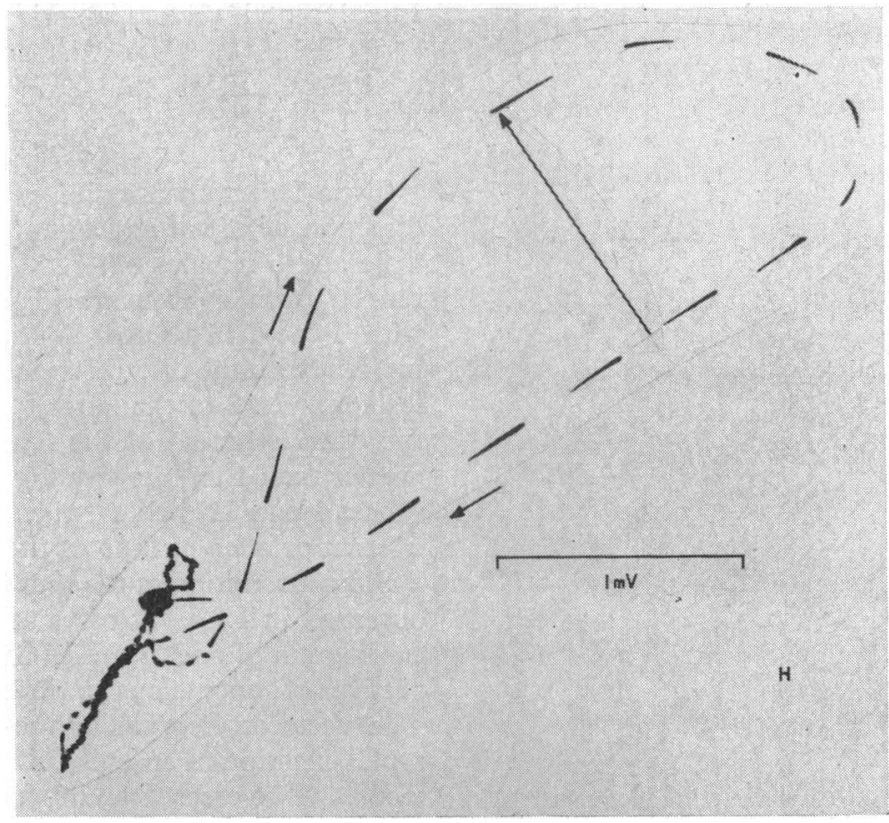

FIG. 2.-Type I QRS $\mathrm{B}$ loop, Case 12, possessing characteristics of hypertrophic obstructive cardiomyopathy. In addition to the magnitude and orientation of the main vector, note the width $(1.0 \mathrm{mV})$ of the distal segment (arrow), the initial slow inscription (28 msec.), and the enlarged posteriorly displaced $P$ loop. (Original vectorcardiogram has been retouched.)

T wave was discordant in 12 out of 19 (horizontal plane), 8 out of 19 (frontal plane), and 15 out of 19 cases (R.Sag plane).

Type II vectorcardiograms were found in 5 female patients ranging in age from 9 to 48 years (Table II). Initial slowing was less apparent in Type II, and the loop was entirely counterclockwise except for one case with a figure-of-eight $\mathbf{Q R S}_{\mathrm{B}}$ loop. The scalar electrocardiogram in all cases may be interpreted as left ventricular hypertrophy with "septal fibrosis", or "incomplete left bundle-branch block". In addition to these findings, Case 21 (Fig. 6) resembled anomalous atrioventricular excitation. A small "pigtail curl" was noted early on the efferent limb of the $Q R S_{\text {R.Sag }}$ loop in Case 23. The $T$ wave was discordant in the horizontal plane in 3 out of 5 , in the frontal plane in 3 out of 5, and in the R.Sag plane in 2 out of 5 cases. The main $P$ wave vector was greater than $0.25 \mathrm{mV}$ in only one instance. ST vector was superiorly and to the right in 1 case.

Type III vectorcardiograms occurred in 9 patients, 5 male and 4 female, ranging in age from 14 to 45 years (Table III). In Cases 29 and 30, the $\mathrm{QRS}_{\mathrm{H}}$ loop was inscribed entirely in a clockwise fashion (Fig. 7 and 8A). In one of these (Case 30, Fig. 7) all three planes were inscribed abnormally and there was a conduction delay throughout the

TABLE II

COMPARISON OF CLINICAL, HAEMODYNAMIC, AND ELECTROCARDIOGRAPHIC FINDINGS IN TYPE II HYPERTROPHIC OBSTRUCTIVE CARDIOMYOPATHY

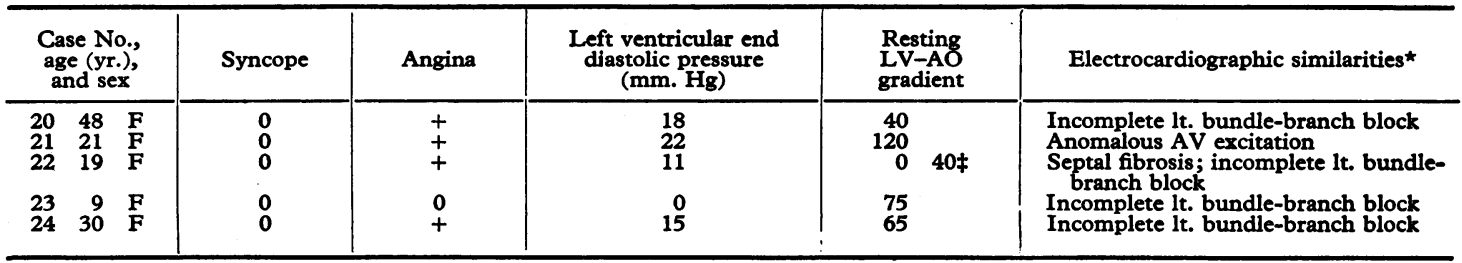

* QRS findings other than left ventricular hypertrophy. 


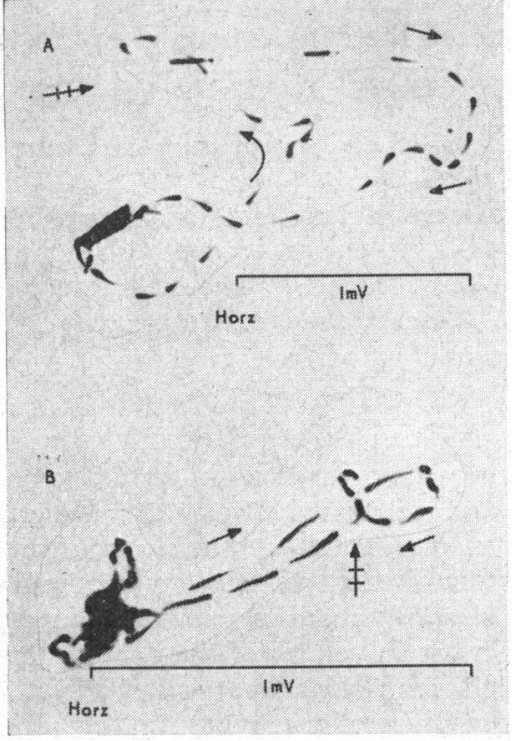

FIG. 3.-Two Type I vectorcardiograms (A, Case 1; B, Case 2) with (hatched arrows) "pigtail curl" deformities. In Fig. A, the abrupt changes in direction, peripheral loop deformities, duration of inscription, and excessive width (approximately $1.5 \mathrm{mV}$ ) of the distal figure-of-eight loop are suggestive vectorcardiographically of hypertrophic obstructive cardiomyopathy. (Original

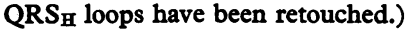

whole loop (duration $114 \mathrm{msec}$.). In the other (Case 29) the $\mathrm{QRS}_{\mathrm{H}}$ loop duration was $84 \mathrm{msec}$. One Type III QRS $S_{\mathrm{H}}$ loop (Case 29, Fig. 9) showed an initial activation posteriorly and to the left and then inscribed a small clockwise "pigtail curl" within the first $24 \mathrm{msec}$. The remainder of the $\mathrm{QRS}_{\mathrm{B}}$ loop was inscribed counterclockwise, posteriorly $\left(-80^{\circ}\right)$, and with a large $(2.5 \mathrm{mV})$ main vector. The "pig-

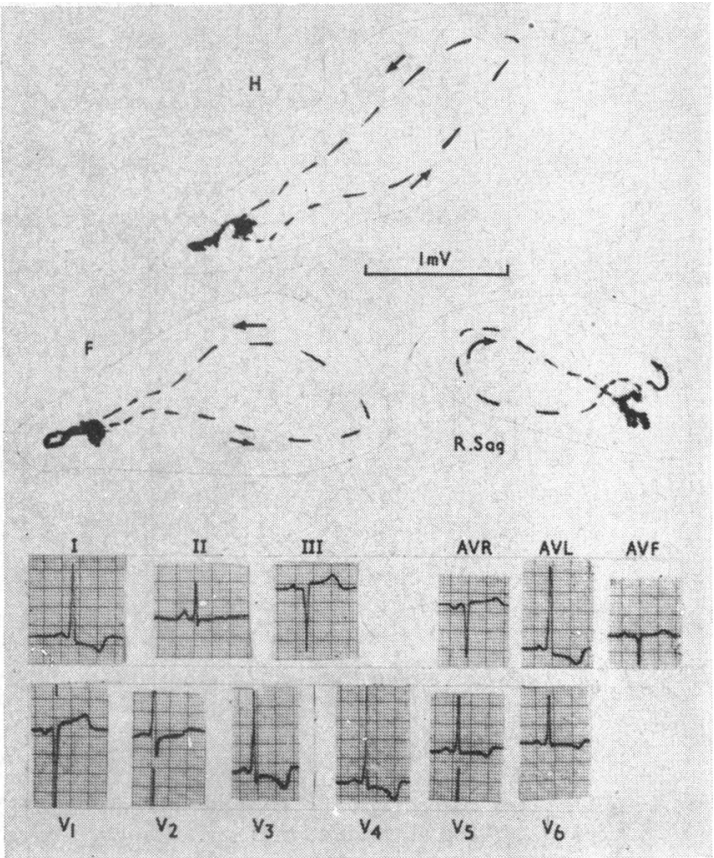

FIG. 4.-Slow septal inscription following an anteriorly

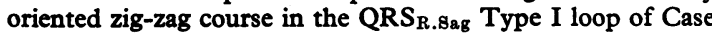
15. The standard electrocardiogram resembles anomalous atrioventricular excitation in the praecordial leads. Early rightward horizontal forces lost in retouching and reproduction.

tail curl" was also seen in the frontal plane. The remaining 6 cases demonstrated counterclockwise inscription of the $Q R S_{\mathrm{H}}$ loop.

The $T$ wave was discordant in all planes except for two $\mathrm{QRS}_{\mathrm{F}}$ loops. The main $\mathrm{P}$ wave vector was greater than $0.25 \mathrm{mV}$ in 2 cases, reaching $0.64 \mathrm{mV}$ in one instance (Fig. 7).

Although the direction of the initial septal vectors

TABLE III

COMPARISON OF CLINICAL, HAEMODYNAMIC, AND ELECTROCARDIOGRAPHIC FINDINGS IN TYPE III HYPERTROPHIC OBSTRUCTIVE CARDIOMYOPATHY

\begin{tabular}{|c|c|c|c|c|c|c|c|}
\hline \multicolumn{3}{|c|}{$\begin{array}{l}\text { Case No., } \\
\text { age (yr.), } \\
\text { and sex }\end{array}$} & Syncope & Angina & $\begin{array}{l}\text { Left ventricular end } \\
\text { diastolic pressure } \\
\text { (mm. Hg) }\end{array}$ & $\begin{array}{l}\text { Resting } \\
\text { LV-AO } \\
\text { gradient }\end{array}$ & Electrocardiographic similarities* \\
\hline $\begin{array}{l}25 \\
26 \\
27\end{array}$ & $\begin{array}{l}38 \\
25 \\
30\end{array}$ & $\begin{array}{l}\mathbf{M} \\
\mathbf{M}\end{array}$ & $\begin{array}{l}0 \\
+ \\
0\end{array}$ & $\begin{array}{l}+ \\
0 \\
0\end{array}$ & $\begin{array}{l}15 \\
20 \\
15\end{array}$ & $\begin{array}{r}130 \\
0 \\
110\end{array}$ & $\begin{array}{l}\text { Incomplete lt. bundle-branch block } \\
\text { Anterior wall infarction } \\
\text { Septal fibrosis; incomplete lt. bundle- }\end{array}$ \\
\hline 28 & 14 & $\mathbf{M}$ & 0 & 0 & 13 & $0 \quad 40 \ddagger$ & Septal fibrosis; incomplete lt. bundle- \\
\hline $\begin{array}{l}29 \\
30 \\
31 \\
32\end{array}$ & $\begin{array}{l}45 \\
16 \\
30 \\
36\end{array}$ & $\begin{array}{l}\mathbf{F} \\
\mathbf{M} \\
\mathbf{M}\end{array}$ & $\begin{array}{l}0 \\
0 \\
+ \\
0\end{array}$ & $\begin{array}{l}+ \\
+ \\
0 \\
+\end{array}$ & $\begin{array}{r}25 \\
25 \\
5 \\
12\end{array}$ & $\begin{array}{rr}50 & \\
0 & 50 \ddagger \\
0 & \\
0 & 60 \ddagger\end{array}$ & $\begin{array}{l}\text { Anterior wall infarction } \\
\text { Lt. bundle-branch block } \\
\text { Lt. axis deviation } \\
\text { Anterior wall infarction; lt. axis }\end{array}$ \\
\hline & 42 & $\mathbf{F}$ & 0 & + & 一 & - & $\begin{array}{l}\text { Anterior wall infarction; } 1 \text { t. axis } \\
\text { deviation }\end{array}$ \\
\hline
\end{tabular}

* QRS findings other than left ventricular hypertrophy.

,+ present; 0 , absent; -, not measured; $\neq$, induced gradient. 


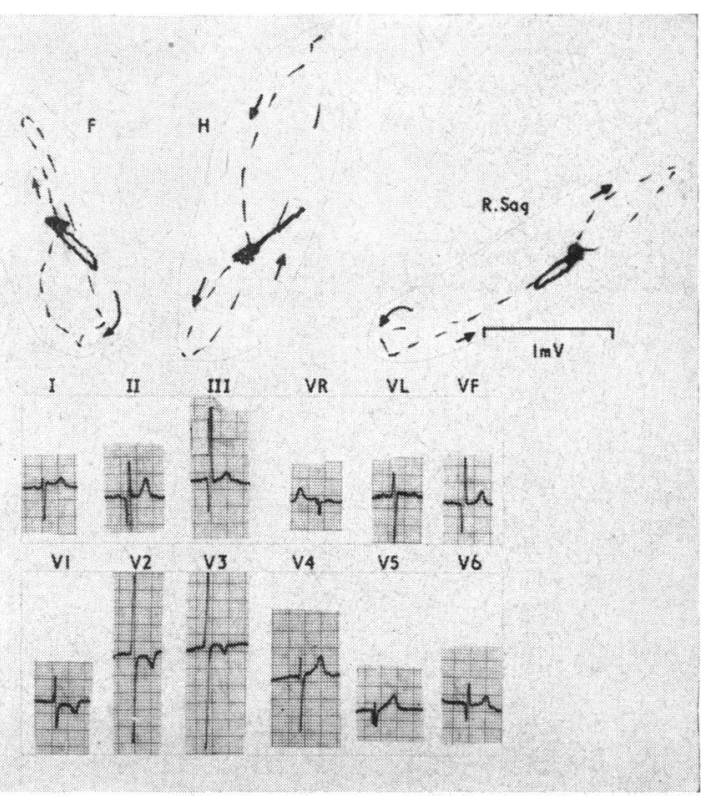

FIG. 5.-Type I vectorcardiogram of a 4-year-old boy (Case 8) with negligible transseptal conduction delay. Note the large $(1.0 \mathrm{mV})$ anterior, rightward, and superiorly oriented main septal vector associated with a large posteriorly directed $\mathbf{R}$ vector. The standard electrocardiogram suggests right ventricular hypertrophy with inferior and lateral wall myocardial infarctions. (Minor retouching of original vectorcardiogram.)

of the $\mathrm{QRS}$ loop was selected for this classification, there was no relation of these septal vectors to the direction of the initial septal vectors in the frontal and R.Sag planes. There was no apparent correlation between the clinical findings or the left ventricular haemodynamic findings and the type of QRS $_{\mathrm{H}}$ loop (Table I, II, and III). The familial cases (Cases 18 and 33) of the series were Type I and III $\mathrm{QRS}_{\mathrm{H}}$ loops.

There were 5 instances of left axis deviation $\left(-30^{\circ} \mathrm{AQRS} \mathrm{S}_{\mathrm{F}}\right)$, one associated with right bundlebranch block (Table I). The main P loop axis was noted to be greater than $0.25 \mathrm{mV}$ in only 24 per cent of the cases (Table IV).

\section{Discussion}

An interesting paradox in cardiology concerns the inverse relation between the hypertrophied interventricular septum and its electrocardiographic manifestation. Left ventricular free wall hypertrophy is usually manifest electrocardiographically as an increase in voltage of the depolarizing waves of the left ventricular free wall, whereas the depolarizing waves of the hypertrophied septum are usually smaller in magnitude than normal and are frequently absent (Bryant, 1953; Cabrera and Gaxiola, 1960; Wallace, McCall, and Estes, 1962; Burch and DePasquale, 1960). Cabrera et al. (1958) postulate coronary insufficiency as the explanation of this situation, and Bryant explains the phenomenon as a result of incomplete left bundle-branch block. Wallace et al. (1962) state that spatial reorientation of the initial vectors is an adequate explanation for this finding. Burch and DePasquale (1960) suggest that fibrous replacement of

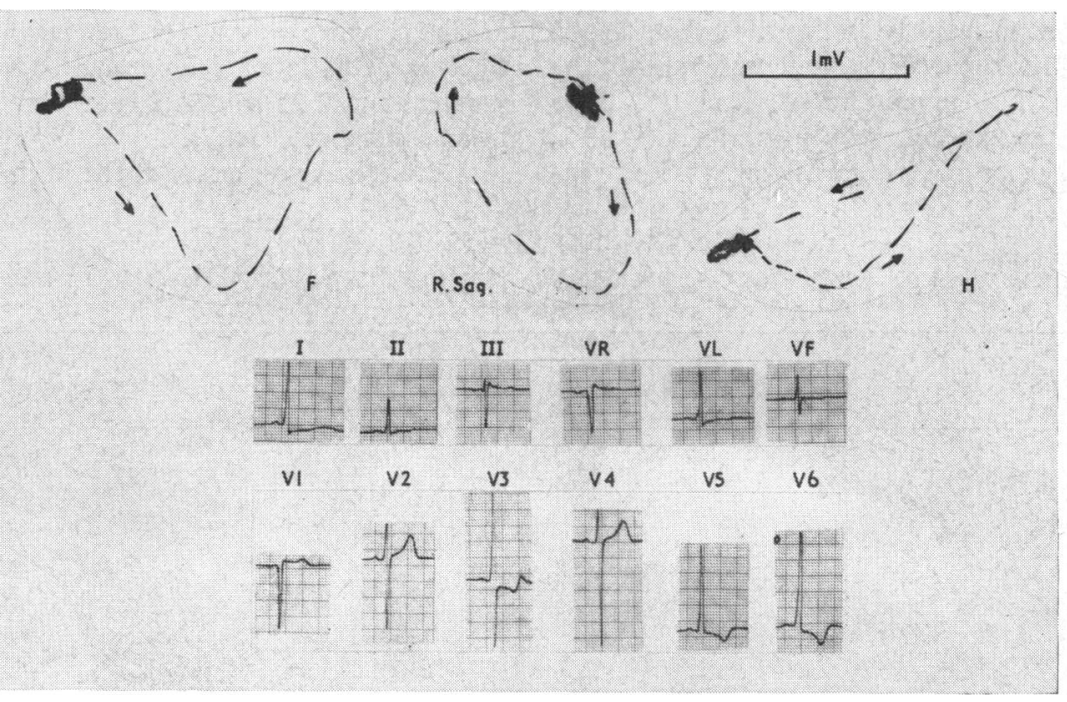

FIG. 6.-Type II vectorcardiogram and standard electrocardiogram of Case 21, both resembling septal fibrosis or first degree incomplete left bundle-branch block. aVL, nearly perpendicular to the efferent $Q R S_{B}$ limb, falsely appears to have a delta wave. 


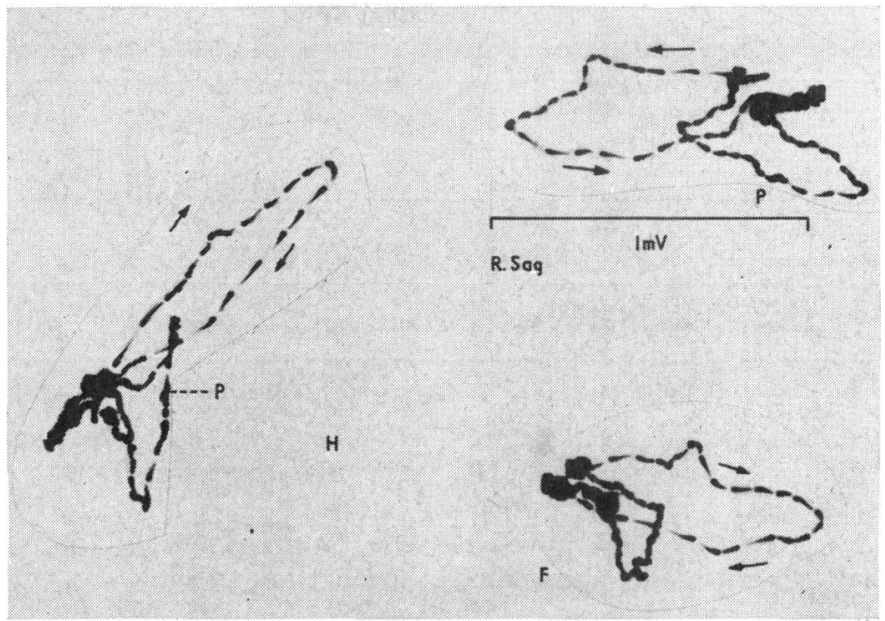

FIG. 7.-Type III vectorcardiogram of Case 30, similar to complete left bundle-branch block in the horizontal plane, demonstrates totally reversed inscription in all three planes. The $P$ loop is exceedingly large $(0.64 \mathrm{mV}$ $P_{R .8 a g}$ ) and open. The latter is PT displacement and not artefactual.

the septal myocardium will reduce the magnitude of the septal vectors by reducing myocardial muscle mass. All investigators agree that septal activation is abnormal but the precise explanation remains elusive.

From this vectorcardiographic analysis in hypertrophic obstructive cardiomyopathy the electrocardiographic paradox of septal hypertrophy is

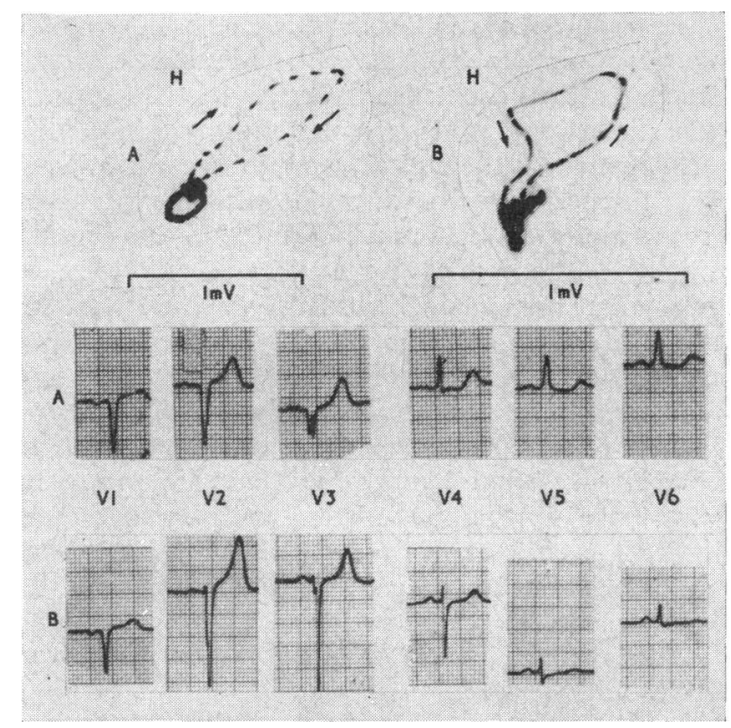

FrG. 8.-Two Type III QRS $\mathrm{Q}_{\mathrm{H}}$ loops, one of normal time duration, (A) with clockwise inscription, Case 29, and (B) Case 26 with counterclockwise inscription. Electrocardiogram in both suggests anterior wall myocardial infarction. approached by considering altered intramural activation processes resulting from the muscle conduction disturbances produced by myocardial hyper-

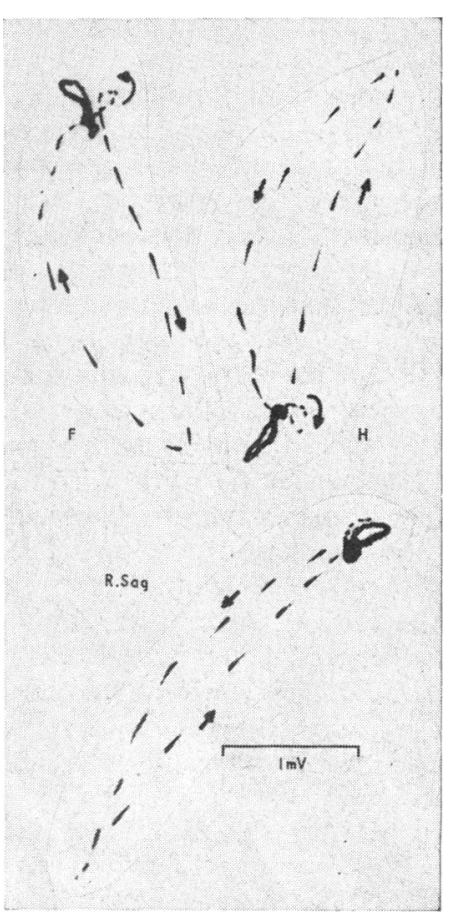

FIG. 9.-A pathognomonic vectorcardiogram in Case 27. The septal "pigtail curl" (initial $24 \mathrm{msec}$.) associated with the

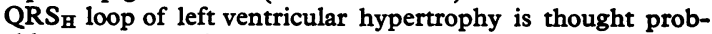
ably to occur only in hypertrophic obstructive cardiomyo- 
TABLE IV

VECTORCARDIOGRAPHIC FINDINGS IN HYPERTROPHIC OBSTRUCTIVE CARDIOMYOPATHY

\begin{tabular}{|c|c|c|c|c|c|c|}
\hline Vectorcardiogram & $\begin{array}{c}\text { Septal } \\
\text { "pigtail curl" }\end{array}$ & $\underset{\text { "pigtail curls" }}{\operatorname{Limb}}$ & $\begin{array}{l}\text { Distal } \\
\text { figure-of-eight } \\
>1.0 \mathrm{mV} \text { width }\end{array}$ & $\begin{array}{l}\text { Main anterior } \\
\text { and right } \\
\text { septal vector } \\
>1.0 \mathrm{mV}\end{array}$ & $\begin{array}{l}\text { Slow septal } \\
\text { inscription }\end{array}$ & $\begin{array}{l}\text { Main P loop } \\
\text { axis }>0.25 \mathrm{mV}\end{array}$ \\
\hline $\begin{array}{l}\text { Type I (19 patients) } \\
\text { Type II (5 patients) } \\
\text { Type III ( } 9 \text { patients) }\end{array}$ & $\begin{array}{l}1 \\
1\end{array}$ & 2 & 2 & 0 & $\begin{array}{r}13 \\
1 \\
2\end{array}$ & $\begin{array}{l}4 \\
1 \\
3\end{array}$ \\
\hline $\begin{array}{l}\text { Total (33) } \\
\text { Percentage }\end{array}$ & $\begin{array}{l}2 \\
6\end{array}$ & $\begin{array}{l}2 \\
6\end{array}$ & $\begin{array}{l}2 \\
6\end{array}$ & $\begin{array}{l}2 \\
6\end{array}$ & $\begin{array}{l}16 \\
48\end{array}$ & $\begin{array}{r}8 \\
24\end{array}$ \\
\hline
\end{tabular}

trophy. Most conduction abnormalities in electrocardiology have been primarily concerned with His Purkinje system disturbances. However, multipolar transmural plunge electrode studies have enabled the intramural activation process to be studied remotely from the Purkinje penetrations. Two observations from these studies are (1) the frequent reversals of the intramural activation process, that is, finding intramural areas of myocardium activated before subadjacent endocardial areas (Scher and Young, 1957; Crocker and Smith, 1965), and (2) the amount of tangential or perpendicular spread of the activation process in reference to the endocardial and epicardial plane (Pruitt, Watt, and Murdo, 1964). The tangential spread is also supported by the rS QRS complexes recorded epicardially in primates and man (Pruitt et al., 1964; Barbato, 1957). Durrer, Roos, and van Dam's (1966) findings in a patient with an ostium primum defect are interpreted as tangential spread of the intramural activation process one centimetre from the endocardium in the postero-basal left ventricular free wall. Lepeschkin (1957) believes that the activation process of the muscle fibres proceeds along the long axis of the muscle fibre. It should follow that the transseptal activation process is directly related to the arrangement of the muscle bundles which comprise the septum. The basal and middle thirds of the interventricular septum are comprised of the deep bulbospiral and deep sino-spiral muscles. The superficial bulbo-spiral and superficial sino-spiral muscles make up the apical third of the septum (Robb and Robb, 1942; Wartman and Souders, 1950). The muscle bundles of the different groups lace the septum in various planes, and this may account for much of the electromotive force cancellation in the septum. Septal activation begins on the lower left septum and is followed very shortly by envelopment from the right lower septum (Scher and Young, 1957; Amer et al., 1960). The anteriorly rightward and superiorly directed electromotive forces of the double envelopment predominate.

What are the factors in hypertrophic obstructive cardiomyopathy that alter transseptal activation?
Histologically the muscle fibres are larger than those seen in hypertrophy from other causes (Teare, 1958; Goodwin et al., 1960; Hollman et al., 1960), and the bizarrely arranged muscle bundles are interspersed with fibrous tissue and endothelial lined clefts. The septum may measure up to $4-6 \mathrm{~cm}$. in width. Electrophysiologically increasing the size of the fibre requires a longer time for depolarization and an increase in muscle mass will increase conduction time through the mass. Conduction across myocardial fibres may take place along a zig-zag path (Lepeschkin, 1957) and will take a much longer time (Pruitt, Essex, and Burchell, 1951). Conduction across fibrous tissue is presumed to be delayed.

From this study in hypertrophic obstructive cardiomyopathy, the above factors are presumed to modify the intramural activation process in such a manner that certain vectorcardiographic peculiarities and three types of vectorcardiograms may be recognized. Of the Type I QRS $\mathrm{H}$ loop there are two cases (6 and 8) of rapid transseptal activation, where the main septal vectors are of such magnitude as to suggest right ventricular hypertrophy. It appears that delay due to transseptal muscle conduction disturbances is negligible, and in these instances septal hypertrophy masquerades as right ventricular hypertrophy. Wigle and Baron (1966) noted considerable diminution of the main septal vector of two young patients with this Type I QRS $S_{\mathrm{H}}$ loop after operation. Their observations of reduced magnitude of septal vectors after ventriculomyotomy corroborate the finding that under certain circumstances of septal activation and transseptal muscle conduction septal hypertrophy may mimic right ventricular hypertrophy. The main septal vectors in these youths, of this magnitude and orientation, are recorded as large "pathological" q waves in the left praecordial scalar leads, and when the same vector is superiorly orientated abnormal inferior $q$ waves are recorded.

In the remaining cases of Type I $\mathrm{QRS}_{\mathrm{H}}$ loops the septal vector is small and usually slowly inscribed. Muscle fibre hypertrophy, muscle bundle disarrangement, fibrous interspersement, increased 
muscle mass, and increased septal distance, with tangential spread of the activation process, are thought to produce muscle conduction abnormalities that slow transseptal conduction and permit cancellation of the enveloping electromotive forces. The usual slowly inscribed septal vector (Table IV) associated with a P-R interval of 0.12 sec., as recorded by the scalar method, often resembled anomalous atrioventricular excitation (Tables I and II). The slow septal inscription, however, was shorter in duration than 75 per cent of the delta waves reported by Chung, Walsh, and Massie (1965) in the Wolff-Parkinson-White syndrome.

In two Type I $Q R S_{\mathrm{H}}$ loops curious small "pigtail curls" were noted on the afferent or efferent limb of a figure-of-eight $\mathrm{QRS}_{\mathrm{H}}$ loop (Fig. 3). These deformities are frequently seen in the efferent limb of the $\mathrm{QRS}_{\mathrm{R} \text {.Sag }}$ loop in right bundle-branch block. "Pigtail curls" are infrequently seen in the horizontal plane (excluding the tip of the $Q R S_{\mathrm{H}}$ loop) and when noted in this plane, without major associated His bundle conduction disturbances, they are interpreted as altered intramural activation processes from muscle conduction disturbances. These curious curls are thought to be instantaneous resultant vectorial imbalances caused by aberrations of the tangential intramural activation process secondary to the muscle conduction disturbances produced by this disease (see above). Changes in direction, magnitude, or speed of conduction from myocardial infarction or myocardial hypertrophy from other causes will often deform the $Q R S_{\mathrm{H}}$ loop but rarely produce the "pigtail curls" on the afferent or efferent limb $\mathrm{QRS}_{\mathrm{H}}$ loop. The "pigtail curls" are especially important when they are large, critically situated, and free of major His bundle conduction disturbances.

In addition to the slow initial inscription and "pigtail curls" of intramural muscle conduction disturbances, two cases of Type I QRS $\mathrm{H}$ loops (Fig. 2 and 3) demonstrated figure-of-eight horizontal loops that had an abnormally wide distal segment which was thought to be indicative of the massive left ventricular hypertrophy of obstructive cardiomyopathy. Figure-of-eight loops in left ventricular hypertrophy usually are narrow; however, in both of these cases the width of the distal segment was at least $1 \mathrm{mV}$.

The transseptal activation in Type II QRS $\mathrm{QH}_{\mathrm{H}}$ loops is altered by the same muscle conduction disturbances in such a manner that the instantaneous vectors of initial septal activation are directed anteriorly and to the left.

Type II QRS ${ }_{\mathrm{H}}$ loops (Fig. 6), like the scalar electrocardiogram in these cases, resemble incomplete left bundle-branch block or septal fibrosis (Table I).
The theory of muscle conduction disturbances secondary to hypertrophy is preferred to the controversial concept of incomplete left bundle-branch block (Leighton et al., 1967) as the explanation for the vector and electrocardiographic abnormalities of septal depolarization. Septal fibrosis is thought to contribute to this type of $\mathrm{QRS}_{\mathrm{H}}$ loop by altering muscle conduction rather than by the proposed theory of fibrous replacement of the myocardium.

The most striking example of aberrant transseptal activation is noted in a Type III loop (Fig. 9). The slowly inscribed "pigtail curl" of septal origin associated with a large (main $Q R S_{H}$ vector $2.5 \mathrm{mV}$ ) posteriorly displaced loop $\left(-80^{\circ}\right)$ is considered pathognomonic for the massive interventricular septal hypertrophy, as seen in hypertrophic obstructive cardiomyopathy. The septal hypertrophy in this disorder is thought to be the only condition able to produce this degree of distorted transseptal activation. One of the vectorcardiographic series (Estes et al., 1963) contained two instances of septal "pigtail curls"; however, the authors did not emphasize this finding.

The afferent and efferent limb "pigtail curls" are thought to be suggestive of hypertrophic obstructive cardiomyopathy, though probably not diagnostic. It is to be anticipated that these $\mathrm{QRS}_{\mathrm{H}}$ loop "pigtail curls" may be found in any condition that produces intramural muscle conduction disturbances; however, they are most likely to be found with massive left ventricular hypertrophy when not associated with major His Purkinje conduction disturbances.

The Type III $\mathrm{QRS}_{\mathrm{H}}$ loop when associated with a clockwise inscription of the horizontal loop is to be distinguished from left bundle-branch block. This difference is apparent (Case 29) (Fig. 8A) where the loop duration is $84 \mathrm{msec}$. With Case 30 (Fig. 7) the situation is more complex, since the $\mathrm{QRS}_{\mathrm{H}}$ duration is 116 msec. The $Q R S_{\mathrm{H}}$ loop morphology cannot be attributed entirely to left bundle-branch block, since all loops are inscribed entirely in reverse order. Reversed inscription of all three loops has been found by Bell, Pugh, and Dunn (1968) in left ventricular hypertrophy from aortic valvular stenosis. It is difficult to exclude entirely a left bundlebranch conduction delay in this case, but altered intramural activation processes from the muscle conduction disturbances of hypertrophy most probably contribute to the abnormal inscription in all three loops.

Type III vectorcardiographic loops contain those cases where the scalar electrocardiogram and the vectorcardiogram resemble anterior wall infarction, a not uncommon finding in hypertrophic obstructive cardiomyopathy (Fig. 8). None of the patients, 
however, had a clinical history of myocardial infarction.

The vectorcardiogram is considered diagnostic of this condition when a large septal "pigtail curl" is inscribed in a $\mathrm{QRS}_{\mathrm{H}}$ loop that is otherwise normal or resembles left ventricular hypertrophy. The vectorcardiographic diagnosis may be implied when there are critically situated "pigtail curls" on the afferent and efferent limbs of the $Q R S_{H}$ loop, or the efferent limb of the $Q R S_{R . S a g}$, when the main anterior and rightward septal vector is greater than 1 $\mathrm{mV}$, and when the width of the distal segment of a $\mathrm{QRS}_{\mathrm{H}}$ figure-of-eight loop exceeds $1 \mathrm{mV}$. Should the combination of slow septal inscription, a large main $P$ vector, the peripheral loop deformities reported by Oberwittler et al. (1965), and left ventricular hypertrophy be noted, then the diagnosis of hypertrophic obstructive cardiomyopathy is to be considered. The types of vectorcardiographic loops seen in this condition aid in classifying the abnormalities, imply transseptal muscle conduction disturbances secondary to myocardial hypertrophy, and simplify the understanding of the unusual electrocardiographic findings.

In conclusion, though there is no definite correlation between the haemodynamic, clinical, and vectorcardiographic findings, it does appear that angina is more prevalent in Types II and III than in Type I (Tables I, II, and III). The obstructive haemodynamic findings seem to follow this same trend, being slightly more severe in Types II and III than in Type I (Tables I, II, and III). The left ventricular compliance as measured by the left ventricular end-diastolic pressure, however, appears to be equally affected in all types (Tables I, II, and III). At this time one can only speculate upon the vectorcardiographic, clinical, and haemodynamic relationship.

\section{SUMMARY}

Three types of $\mathrm{QRS}_{\mathrm{H}}$ loops are classified by the direction of the initial vectors of septal activation; Type I, anteriorly and to the right; Type II, anteriorly and to the left; and Type III, posteriorly and to the left. The unusual electrocardiographic findings in hypertrophic obstructive cardiomyopathy are discussed in relation to the $Q R S_{H}$ loop type.

Vectorcardiographic $Q R S_{H}$ loop characteristics include pathognomonic "pigtail curls" inscribed within the time of septal activation in a $Q R S_{\mathrm{H}}$ loop free of major His Purkinje conduction disturbances. Similar "pigtail loops", critically placed on the efferent or the afferent limb of the $Q R S_{H}$ loop or the efferent limb of the $Q R S_{R . S a g}$ loop, are suggestive of the massive left ventricular hypertrophy found in obstructive cardiomyopathy. When the distal segment of a figure-of-eight $\mathrm{QRS}_{\mathrm{H}}$ loop exceeds $1.0 \mathrm{mV}$ in width, left ventricular hypertrophy from obstructive cardiomyopathy is suggested. Slow inscription of the septal vectors is a common finding in this disorder and when associated with a short $\mathrm{P}-\mathrm{R}$ interval, 0.12 sec. (scalar electrocardiogram), often resembles anomalous atrioventricular excitation.

Alterations in the transseptal activation process by muscle conduction disturbances secondary to myocardial hypertrophy in hypertrophic obstructive cardiomyopathy are thought to explain better some of the vectorcardiographic and electrocardiographic findings known as septal fibrosis or incomplete left bundle-branch block.

I would like to thank Professor J. F. Goodwin for the opportunity to perform this study and to acknowledge the interest and assistance of Dr. Celia Oakley.

\section{REFERENCES}

Amer, N. S., Stuckey, J. H., Hoffman, B. F., Capelletti, R. R., and Domingo, R. T. (1960). Activation of the interventricular septal myocardium studied during cardiopulmonary bypass. Amer. Heart F., 59, 224.

Barbato, E. N. (1957). Personal communication to Lepeschkin (1957).

Bell, H., Pugh, D., and Dunn, M. (1968). Vectorcardiographic evolution of left ventricular hypertrophy. Brit. Heart $\mathcal{f}$., 30, 70.

Braudo, M., Wigle, E. D., and Keith, J. D. (1964). A distinctive electrocardiogram in muscular subaortic stenosis due to ventricular septal hypertrophy. Amer. $\mathcal{F}$. Cardiol., 14, 599.

Braunwald, E., Morrow, A. G., Cornell, W. P., Aygen, M. M., and Hilbish, T. F. (1960). Idiopathic hypertrophic subaortic stenosis. Clinical, hemodynamic and angiographic manifestations. Amer. F. Med., 29, 924.

Bryant, J. M. (1953). Intraventricular conduction. In $A d-$ vances in Electrocardiography, p. 159 . Ed. by C. E. Kossmann. Grune and Stratton, New York.

Burch, G. E., and DePasquale, N. (1960). A study at autopsy of the relation of absence of the $Q$ wave in leads $I, a_{L}$, $\mathrm{V}_{5}$ and $\mathrm{V}_{6}$ to septal fibrosis. Amer. Heart $\mathcal{7}$., 60, 336 .

Cabrera, E., Garcia-Font, R., Gaxiola, A., and Pileggi, F. (1958). The vectorcardiogram of ventricular activation in chronic coronary heart disease. Amer. Heart f., $55,557$.

- and Gaxiola, A. (1960). Diagnostic contribution of the vectorcardiogram in hemodynamic overloading of the heart. Amer. Heart F., 60, 296.

Chung, K. Y., Walsh, T. J., and Massie, E. (1965). WolffParkinson-White syndrome. Amer. Heart f., 69, 116.

Cohen, J., Effat, H., Goodwin, J. F., Oakley, C. M., and Steiner, R. E. (1964). Hypertrophic obstructive cardiomyopathy. Brit. Heart f., 26, 16.

Crocker, H. D., and Smith, C. R. (1965). The ventricular activation process in cattle. Ann. N.Y. Acad. Sci., 127, Art. 1, 179.

Durrer, D., Roos, J. P., and van Dam, R. Th. (1966). The genesis of the electrocardiogram of patients with ostium primum defects. Amer. Heart f., 71, 642. 
Estes, E. H., Whalen, R. E., Roberts, S. R., and McIntosh, H. D. (1963). The electrocardiographic and vectorcardiographic findings in idiopathic hypertrophic subaortic stenosis. Amer. Heart fु, 65, 155.

Goodwin, J. F., Hollman, A., Cleland, W. P., and Teare, D. (1960). Obstructive cardiomyopathy simulating aortic stenosis. Brit. Heart f., 22, 403.

Hollister, R. M., and Goodwin, J. F. (1963). The electrocardiogram in cardiomyopathy. Brit. Heart f., 25, 357.

Hollman, A., Goodwin, J. F., Teare, D., and Renwick, J. W. (1960). A family with obstructive cardiomyopathy (asymmetrical hypertrophy). Brit. Heart f., 22, 449.

Leighton, R. F., Ryan, J. M., Goodwin, R. S., Wooley, C. F., and Weissler, A. M. (1967). Incomplete left bundlebranch block. The view from transseptal intraventricular leads. Circulation, 36, 261.

Lepeschkin, E. (1957). Discussion. In The electrophysiology of the heart. Ann. N.Y. Acad. Sci., 65, Art. 6, 823.

Marriott, H. J. L. (1964). Electrocardiographic abnormalities, conduction disorders and arrhythmias in primary myocardial disease. Progr. cardiovasc. Dis., 7, 99.

Oberwittler, W., Portheine, H., Bender, F., and Reploh, H. D. (1965). Elektrokardiographische und vektordiagraphische Befunde bei hypertrophischer Subaortenstenose. Z.Kreisl.-Forsch., 54, 147.

Prescott, R., Quinn, J. S., and Littmann, D. (1963). Electrocardiographic changes in hypertrophic subaortic stenosis which simulate myocardial infarction. Amer. Heart f., 66, 42.

Pruitt, R. D., Essex, H. E., and Burchell, H. B. (1951). Studies on the spread of excitation through the ventricular myocardium. Circulation, 3, 418.
-, Watt, T. B., and Murdo, S. (1964). Left axis deviation: its relation to experimentally induced lesions of the anterior left bundle-branch system in canine and primate hearts. Ann. N.Y. Acad. Sci., 127, Art. 1, 204.

Robb, J. S., and Robb, R. C. (1942). The normal heart. Anatomy and physiology of the structural units. Amer. Heart f., 23, 455.

Scher, A. M., and Young, A. C. (1957). Ventricular depolarization and the genesis of QRS. Ann. N.Y. Acad. Sci., 65, Art. 6, 768.

Sodi-Pallares, D., Brancato, R. W., Pileggi, F., Medrano, G. A., Bisteni, A., and Barbato, E. (1957). The ventricular activation and the vectorcardiographic curve. Amer. Heart f., 54, 498.

Sokolow, M., and Lyon, T. P. (1949). The ventricular complex in left ventricular hypertrophy as obtained by unipolar precordial and limb leads. Amer. Heart f., 37, 161.

Teare, D. (1958). Asymmetrical hypertrophy of the heart in young adults. Brit. Heart $\mathcal{F}$., 20, 1 .

Wallace, A. G., McCall, B. W., and Estes, E. H. (1962). The vectorcardiogram in left ventricular hypertrophy. Amer. Heart f., 63, 466.

Wartman, W. B., and Souders, J. C. (1950). Localization of myocardial infarcts with respect to the muscle bundles of the heart. Arch. Path., 50, 329.

Wigle, E. D., and Baron, R. H. (1966). The electrocardiogram in muscular subaortic stenosis. Circulation, 34, 585.

Wood, R. S., Taylor, W. J., Wheat, M. W., and Schiebler, G. L. (1962). Muscular subaortic stenosis in childhood. Pediatrics, 30, 749. 